\title{
Experimental investigation on the performance of residential air conditioning system using water condensate for subcooling
}

\author{
Kasni Sumeru, Triaji Pangripto Pramudantoro, and Andriyanto Setyawan* \\ Refrigeration and Air Conditioning Engineering Department, Politeknik Negeri Bandung, Bandung 40012, Indonesia
}

\begin{abstract}
The experimental investigation of subcooling effects on system COP was carried out on a residential air conditioning using $\mathrm{R} 410 \mathrm{~A}$ as working fluid, with a compressor capacity of about $0.75 \mathrm{~kW}$. In the experiment, the indoor and outdoor temperatures were controlled at $24^{\circ} \mathrm{C}$ and $32^{\circ} \mathrm{C}$. The results showed that the use of condensate water lowers the refrigerant temperature in the condenser outlet by $2.7^{\circ} \mathrm{C}$. By lowering the refrigerant temperature, the cooling capacity of the air conditioning can be enhanced. The decrease in of refrigerant temperature results in COP improvement $16.4 \%$. Besides increasing the COP, the condensate water also decreases the discharge compressor temperature by $7.6^{\circ} \mathrm{C}$. The decrease in of the discharge compressor temperature resulted in the decrease in power consumption of the air conditioning system by $5.9 \%$.
\end{abstract}

\section{Introduction}

It is well known that air conditioning (AC) system consumes the biggest energy in buildings. In hot countries, residential sector consumes about $60 \%$ for energy of air conditioning system [1]. To reduce the power consumption of the AC, several methods have been investigated by researchers, such as using inverter to regulate the compressor speed [2-4], using ejector as an expansion device [5-8] and inserting nanoparticles in the compressor lubricant [9-11]. Using condensate water to reduce the temperature of the discharge compressor is also a method to enhance the AC performance. The temperature difference between condensate water and discharge compressor is quite high. As a result, there is the potential for condensate water to absorb heat from discharge compressor. Because some part of heat has been absorbed by the condensate water, so that there will be subcooling on the condenser outlet. To the best of my knowledge, no reference discuss about the use of condensate water to generate subcooling in AC system. The subcooling on the AC system will increase the cooling capacity. The increase in cooling capacity will reduce the power consumption of $\mathrm{AC}$ for the same cooling capacity.

The use of condensate water to lower air temperature before entering the condenser to improve the $\mathrm{AC}$ performance has been investigated by several researchers [12-14]. Sawant et al. [12] employed condensate water to lower the air temperature before entering to the condenser of a window air conditioner. In their experiment, they utilized condensate water on the evaporative cooling to decrease the air temperature before passing through the condenser. Their results showed that the evaporative cooling using condensate water decreased power consumption of the AC up to $10 \%$. Another experimental investigation about the use of condensate water on the evaporative cooling to lower the air temperature of condenser was carried out by Sawan et al. in Beirut [13]. The experiment to reduce power consumption was performed on a split type air conditioning unit on June and August and the results were $5 \%$ and $4,5 \%$, respectively. The next investigation how to increase the COP system by lowering air temperature upstream of condenser using water spray was performed by Tissot et al. [15]. The results showed that the use of water spray improved the COP by $28.9 \%$. The use of this method will be advantageous when the water is abundant and inexpensive. The latest experimental investigation of the use of condensate water was carried out by Ibrahim et al. [14]. An air conditioning unit with cooling capacity of 1.5 ton refrigeration was utilized in their experiment. An evaporative cooler using condensate water was employed as precooling the air temperature before entering to the condenser. They reported that the power consumption of compressor was decreased by $6.1 \%$, whereas the COP was increased by $21.4 \%$.

In contrast to the previous described studies, this study will use condensate water to lower the temperature of the compressor discharge. In the present study, the experiment is focused on the use of condensate water as a discharge compressor cooler to increase the $\mathrm{AC}$ performance. The increase in AC performance is caused by subcooling on the condenser outlet. In the experiment, a split-type air conditioning unit using R410A with compressor capacity about $0.75 \mathrm{~kW}$ is employed. Since R22 still has a ODP (ozone depletion potential) property, $\mathrm{R} 410 \mathrm{~A}$ is introduced to replace the

\footnotetext{
"Corresponding author: andriyanto@polban.ac.id
} 
R22. Since 2015, in Indonesia, the use of R22 on a new AC system is prohibited.

\section{Methodology}

The experiments were carried out in a AC test chamber where the relative humidity and dry bulb temperature were be able to controlled. In this investigation, the indoor and outdoor temperatures were controlled at $24^{\circ} \mathrm{C}$ and $32^{\circ} \mathrm{C}$, respectively, whereas the relative humidity at outdoor and indoor were $70 \%$ and $50 \%$, respectively. There are two tests in the experiment, i.e. the first test without condensate water (normal condition) and the second test using a heat exchanger to lower discharge compressor with condensate water to generate subcooling.

A split-type air conditioner with cooling capacity of $2.5 \mathrm{~kW}$ and using R410A as working fluid was utilized in the experiments. In order to investigate the effect of the use of condensate on the system, there are five parameters will be measured, viz.: temperature, pressure, air velocity, electrical current and voltage. There are five instruments are employed to measure those parameters, that is thermometer, pressure gauge, manometer, ammeter and voltmeter. Table 1 shows the accuracies of those instruments. At every 20 minutes was recorded for three hours. Fig. 1 shows the schematic diagram of a split-type air conditioner employ condensate water to lower the temperature of discharge.

Table 1. The accuracies of measuring instruments.

\begin{tabular}{|c|l|l|l|}
\hline No. & Instrument & Measurement & Accuracy \\
\hline 1. & $\begin{array}{l}\text { K-type } \\
\text { thermocouple }\end{array}$ & Temperature & $\pm 0.1^{\circ} \mathrm{C}$ \\
\hline 2. & Pressure gauge & Low pressure & $\pm 0.1 \mathrm{bar}$ \\
\hline 3. & Pressure gauge & High pressure & $\pm 0.5 \mathrm{bar}$ \\
\hline 4. & Manometer & Velocity of air & $\pm 0.1 \mathrm{~m} / \mathrm{s}$ \\
\hline 5. & Voltmeter & Electrical potential & $\pm 1 \mathrm{~V}$ \\
\hline 6. & Ammeter & Electrical current & $\pm 0.1 \mathrm{~A}$ \\
\hline
\end{tabular}

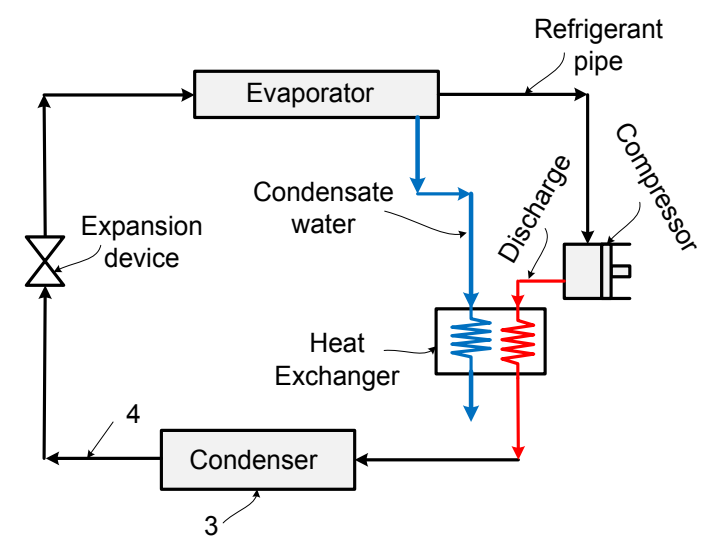

Fig. 1. Schematic diagram of a split-type air conditioner with condensate water to lower the dicharge temperature.

There are five parameters will be presented and analyzed, viz.: degree of subcooling, cooling capacity, discharge temperature, power consumption, and COP when without and with condensate water as discharge cooler. The power in of the system is calculated using Eq. (1). Furthermore, the power consumption is determined using Eq. (2).

$$
\begin{gathered}
P=I . V \\
W_{h}=P . t
\end{gathered}
$$

where,

$P \quad=$ input power, Watt

$I \quad=$ electrical current, ampere

$V \quad=$ electrical potential, volt

$W_{h} \quad=$ Power consumption, $\mathrm{kWh}$

$t \quad=$ time, hour

The cooling capacity is determined using psychrometric chart as shown in Fig. 2. Point 1 represents the air condition before entering the evaporator, whereas point 2 is air condition after pass through the evaporator. To calculate the mass flow rate of air downstream from evaporator, the ducting is installed in the evaporator. The cooling capacity is calculated using Eq. (3) and (4),

$$
\begin{gathered}
Q=n \&\left(h_{1}-h_{2}\right) \\
n k=\rho . v \cdot A
\end{gathered}
$$

where,

$$
\begin{aligned}
Q & =\text { cooling capacity, } \mathrm{kW} \\
h^{\mathrm{S}} \mathrm{k} & =\text { mass flow rate of air, } \mathrm{kg} / \mathrm{s} \\
h_{1} & =\text { spesific enthalpy in point } 1, \mathrm{~kJ} / \mathrm{kg} \\
h_{2} & =\text { spesific enthalpy in point } 2, \mathrm{~kJ} / \mathrm{kg} \\
\rho & =\text { density of air, } \mathrm{kg} / \mathrm{m}^{3} \\
v & =\text { velocity of air, } \mathrm{m} / \mathrm{s} \\
A & =\text { cross section area of ducting, } \mathrm{m}^{2}
\end{aligned}
$$

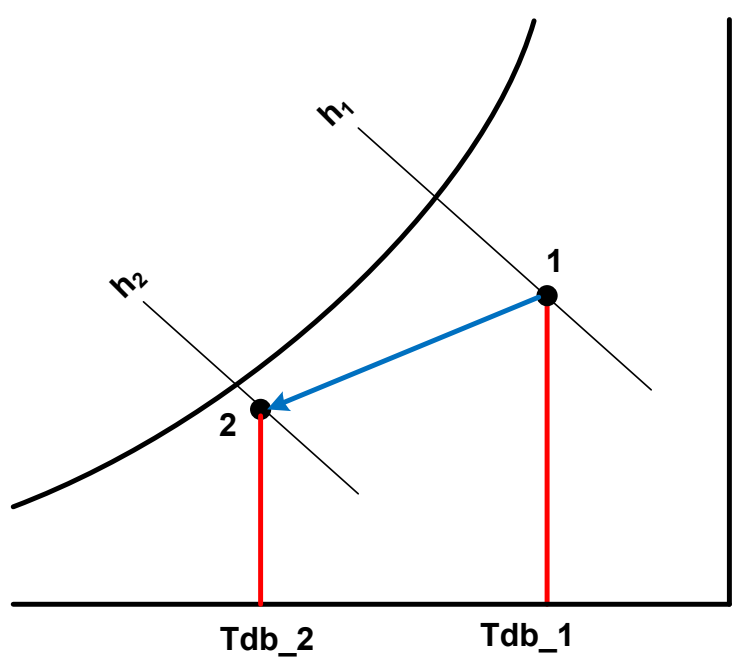

Fig. 2. Psychrometric chart to determine the cooling capacity.

To obtain $h_{1}$ and $h_{2}$, the dry bulb and wet bulb temperatures ( $T_{d b}$ and $\left.T_{w b}\right)$ have to measured using thermometer. 
Coefficient of performance (COP) of $\mathrm{AC}$ is calculated with Eq. 5,

$$
C O P=\frac{Q}{P}
$$

The use of condensate will reduce the power consumption and increase the cooling capacity. The decrease in power input and the increase in cooling capacity lead to the increase the COP. The input power reduction is determined using Eq. (6). Meanwhile, the cooling capacity and COP improvements are calculated using Eq. (7) and (8), respectively.

$$
\begin{gathered}
P_{\text {reduc }}=\frac{P_{\text {with }}-P_{\text {without }}}{P_{\text {with }}} \\
Q_{\text {imp }}=\frac{Q_{\text {with }}-Q_{\text {without }}}{Q_{\text {with }}} \\
C O P_{\text {imp }}=\frac{C O P_{\text {with }}-C O P_{\text {without }}}{C O P_{\text {with }}}
\end{gathered}
$$

\section{Results and Discussions}

As discussed in the previous section that because the temperature of compressor discharge was much higher than that of condensate water, as a result the discharge temperature will decrease when the condensate contact with the discharge, as shown in Fig. 3. The figure shows that for three hours measurement the discharge temperature difference is not constant. However, the discharge temperatures without condensate water are always higher than that of with condensate as a discharge cooler. The average of the discharge temperature difference is $7.6^{\circ} \mathrm{C}$. A decrease in discharge temperature causes a decrease the compressor's electric current.

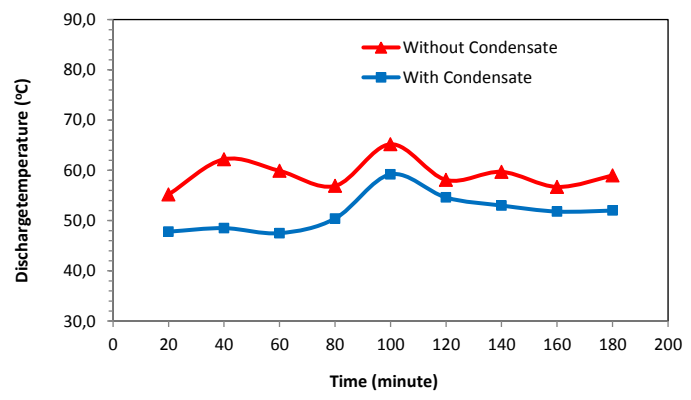

Fig. 3. Comparison of discharge temperature of AC between without and with condensate as a discharge cooler.

By lowering the discharge temperature, leads to the decrease in the input power as shown in Fig. 4. The figure depicts that the input powers with condensate are always lower than that of without condensate. It is observed that the input power difference between without and with condensates is constant, with a difference of 48 Watt. Using Eq. (6), the input power reduction is $5.9 \%$. This input power reduction is very close to the experimental result performed by Ibrahim et al. (2017), that is $6.1 \%$.

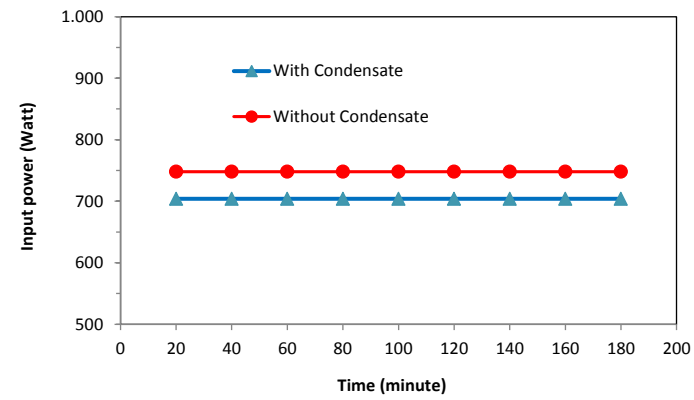

Fig. 4. Comparison of input power of $\mathrm{AC}$ between without and with condensate as a discharge cooler.

As described in the previous passage, the decrease in discharge temperature will be followed by the decrease in temperature of the condenser outlet. Fig 5 depicts the decrease in temperature of the condenser outlet due to condensate water as a discharge cooler. The figure shows that during three hours measurement the temperature differences between without and with condensate water are not constant. At minute of 20 , the temperature difference is still small, only $1,2^{\circ} \mathrm{C}$, whereas at minute of 100 to 140 and at minute of 180 , the temperature difference increases, that is about $3.8^{\circ} \mathrm{C}$ to $4.0^{\circ} \mathrm{C}$. The average of temperature difference between without and with condensate water as subcooler is $2.7^{\circ} \mathrm{C}$.

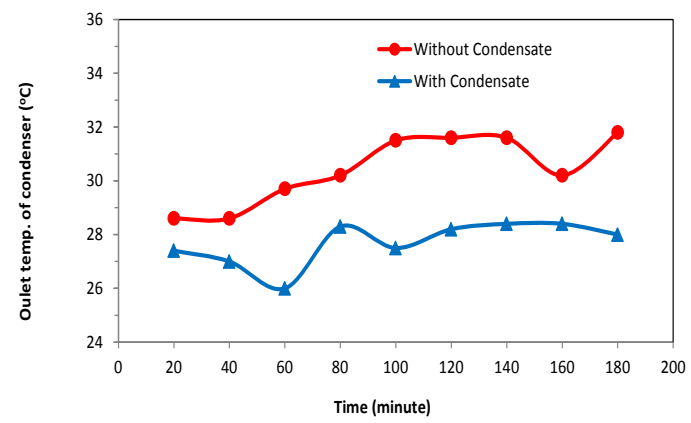

Fig. 5. Comparison of temperature of condenser outlet of AC between without and with condensate as a discharge cooler.

The decrease in temperature of condenser outlet causes subcooling and increase in cooling capacity. Fig. 6 shows the cooling capacities with condensate water are always higher than that of without condensate water. It is observed that the cooling capacity difference between without and with condensates is relatively constant, with an average of 300 Watt. Using Eq. (7), the cooling capacity improvement is $11.2 \%$. The average percentage capacity improvement could be increased when the ambient temperature increases. In the present experimental investigation, the outdoor temperature is $32^{\circ} \mathrm{C}$. Meanwhile, in areas which have a high outdoor, that is $34^{\circ} \mathrm{C}$, such as Jakarta and Surabaya, the percentage improvement of cooling capacity will increase. 


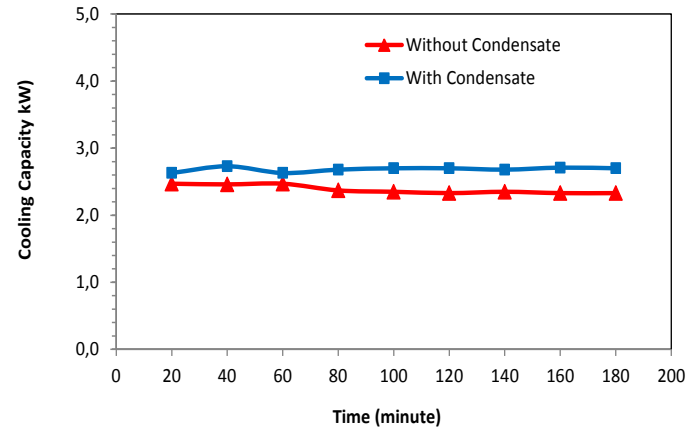

Fig. 6. Comparison of cooling capacity of AC between without and with condensate as a discharge cooler.

The decrease in input power and the increase in cooling capacity lead to increase the COP. Fig. 7 depicts the COPs with condensate water are always higher than that of without condensate water. The figure shows that COP difference between without and with condensates is relatively constant, with an average of 0.6. Using Eq. (8), the COP improvement is $16.4 \%$. This results is slightly higher than the experimental result Britto and Vasanthanathan [16], that is $14.3 \%$. But, compared to investigation by Ibrahim et al. (2017), this experimental result is lower. Ibrahim et al. (2017) reported that the use of condensate water as a pre-cooling air entering the condenser increased the COP by $21.4 \%$.

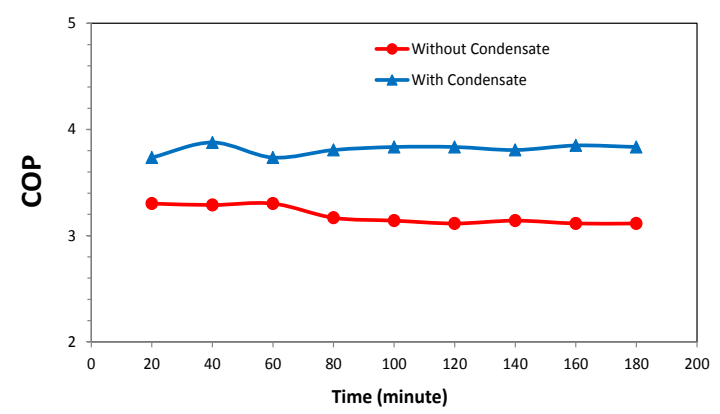

Fig. 7. Comparison of coefficient of performance of AC between without and with condensate as a discharge cooler.

\section{Conclusion}

Based on the experimental investigation, the use of condensate water to lower discharge temperature leads to improve the system performances. The use of condensate water decreases the discharge and the condenser outlet temperatures by $7.6^{\circ} \mathrm{C}$ and $2.7^{\circ} \mathrm{C}$ respectively. It is found that the input power is decreased by $5.9 \%$ as a result of the decrement in discharge temperature. The decrease in condenser outlet temperature increases the cooling capacity by $11.2 \%$. The decrease in input power and the increase in cooling capacity improve the COP by $16.4 \%$.

The authors are grateful to the Minister of Research, Technology and Higher Education, Indonesia for financial support and Politeknik Negeri Bandung for the facilities and management support. This research was carried out under the Penelitian Strategis Nasional: Fund No. 025/SP2H/LT/DRPM/IV/2017.

\section{References}

1. E.M.A. Mokheimer, A.G. Eid, Determinants of consumers' demand on energy-efficiency air conditioners in Saudi Arabia. Energy and Environment 22, 711-722 (2011)

2. S. Shao, W. Shi, X. Li, H. Chen . Performance representation of variable-speed compressor for inverter air conditioners based on experimental data. Internasional Journal of Refrigeration. Vol. 27(8), 805-815 (2004)

3. C.W. Roh and M.S. Kim, Comparison of the heating performance of an inverter-driven heat pump system using R410A vapor-injection into accumulator and compressor. Internasional Journal of Refrigeration. Vol. 35(2), 805-815 (2012)

4. H. Nasution, K. Sumeru, A.A. Aziz, M.Y. Senawi, Performance study of air conditioning control system for building energy saving. Energy Procedia 61, 63-66 (2014)

5. N. Bilir, H.K. Ersoy, Performance improvement of the vapour compression refrigeration cycle by a two-phase constant area ejector. International Journal of Energy Research 33, 469-80 (2009)

6. S. Elbel, Historical and present developments of ejector refrigeration systems with emphasis on transcritical carbon dioxide air-conditioning applications. International Journal of Refrigeration 34, 1545-1561 (2011)

7. K. Sumeru, S. Sulaimon, F.N. Ani, H. Nasution, Numerical study of ejector as an expansion device in split-type air conditioner for energy savings. Journal of Engineering and Thechnological Sciences 45, 179-92 (2013)

8. Sumeru K., Sulaimon S., Ani F.N., Nasution H., , Numerical study of ejector as an expansion device in split-type air conditioner. Applied Mechanics and Materials 388, 101-105. (2013)

9. S. Bi, K. Guo, Z. Liu, J. Wu, Performance of a domestic refrigerator using $\mathrm{TiO}_{2}-\mathrm{R} 600 \mathrm{a}$ nanorefrigerant as working fluid. Energy Conversion Management 52, 733-737 (2011)

10. M. Xing, R. Wang, J. Yu, Application of fullerene C60 nano-oil for performance enhancement of domestic refrigerator compressor. International Journal of Refrigeration 40, 398-403 (2014)

11. K. Sumeru, T.P. Pramudantoro, F.N. Ani, Enhancing air conditioning performance using $\mathrm{TiO} 2$ nanoparcicles in compressor lubricant. Advanced Material Research 1125, 556-560 (2015).

12. A.P. Sawant, N. Agrawal, P. Nanda, Performance assessment of an evaporative cooling-assisted window air conditioner. International Journal of Low-Carbon Technology 7, 128-136 (2011)

13. R. Sawan, K. Ghali, M. Al-Hindi, Use of condensate drain to pre-cool the inlet air to the condensers: a thechnique to improve the performance of split air conditioning units. HVAC\&R Research 18, 37-41 (2012)

14. N.I. Ibrahim, A.A. Al-Farayedhi, P. Gandhidasan, Experimental investigation of a vapor compression system with condenser air pre-cooling by 
condensate. Applied Thermal Engineering 110, 1255-1263 (2017)

15. J.J.J. Britto, A. Vasanthanathan, Performance evaluation of window air cooling system on the condenser, in: Proceeding of Internasional Conference Energy Efficiency Thechnologies for Sustainability, pp. 796-801 (2013)

16. J. Tissot, P. Boulet, F. Trinquet, L. Fournaison, M. Lejeune, F. Liaudet, Imrpoved energy performance of a refrigerating machine using water spray upstream of the condenser. International Journal of Refrigeration. Vol. 38(1), 93-105 (2013) 